\section{Anti-inflammatory drugs in management of spondylosis}

In 1976 we drew attention to the uncertain rationale in the use of anti-inflammatory drugs in the management of osteoarthritis. ${ }^{1}$ We pointed out that osteoarthrosis is not an inflammatory process per primum, though focal inflammatory changes may occur from time to time in any given joint probably brought about by the products of cartilage degradation. Despite this information, available in standard orthopaedic texts, anti-inflammatory drugs are widely administered to patients with osteoarthrosis at considerable cost and to no clear benefit. Indeed, indomethacin has been indicted on more than one occasion for accelerated deterioration of the hip joint in osteoarthrosis." 4 This is probably attributable to the known inhibitory effect of this drug on cartilage ${ }^{1}$ and bone metabolism. ${ }^{5}$ We consider that the published findings represent only the tip of the iceberg.

\section{Methods and results}

The dearth of information and the unbelievable paucity of controlled clinical trials for the use of anti-inflammatory drugs in spondylosis prompted us to carry out a double-blind cross-over trial using indomethacin, flurbiprofen, and placebo in the treatment of symptomatic lumbar spondylosis in adults. Such a trial has not been reported previously. Twenty-four patients were studied; all had chronic symptoms of back pain, leg pain, or both attributable to this disorder, but none were in an acute episode at the time of the trial. Patients received each of the drugs or placebo for two weeks, and the sequence of administration was planned to minimise carry-over effects. Indomethacin was administered at $150 \mathrm{mg}$ daily and flurbiprofen at $300 \mathrm{mg}$ daily.

Eleven of the 24 patients in the trial showed no measurable response to the drugs used. Overall, flurbiprofen was found to be statistically no more effective than placebo in producing patient-assessed pain relief. Indomethacin was more effective in relieving pain than flurbiprofen, but it had a much higher incidence of adverse side effects than flurbiprofen, which was similar to placebo. Slight improvement in spinal flexion, straight leg raising, and response to the femoral nerve stretch test was observed with indomethacin and flurbiprofen, but not with placebo. The improvements in each of these manoeuvres could not be considered as clinically important gains. No correlation was found between the response to the anti-inflammatory drugs and the patient's age, sex, or degree of spondylosis as judged by radiographic criteria. How much of the patient response to drugs was due to analgesia and how much was attributable to a direct anti-inflammatory effect could not be gauged by our study.

\section{Comment}

The indiscriminate use of non-steroidal anti-inflammatory drugs is a cause for wider concern when one considers the size of the back pain population or rather, patients with back pain due to intrinsic spinal disorders-namely, spondylosis, disc prolapse, spondylolisthesis, spinal-canal stenosis, "mechanical inadequacy," and postural abnormalities. In our unit, which devotes its clinical activities almost entirely to spinal disease and disorders, nine out of 10 patients who present with pain due to existing spinal disorders have previously been given anti-inflammatory drugs and two-thirds of them have received indomethacin. What then is the rationale of administering anti-inflammatory drugs to a patient with spondylosis, the most commonly encountered cause of spinal pain in the cervical and lumbar regions? The mechanism of pain production in spondylosis is poorly understood unless there is radicular disease at a foraminal level. The posterior apophyseal joints may show osteoarthrotic changes in spondylosis and even though they are non weight-bearing articulations they may be responsible for part of the clinical picture. There is no evidence for an inflammatory process of a widespread nature throughout the lumbar or cervical regions in active spondylosis. Clinical observations indicate that changes are quite focal.

We conclude that unless inflammatory foci in the lumbar spine associated with spondylosis are shown to be at least dampened by systemic anti-inflammatory drugs there can be no place for their routine use in the treatment of the disease. If, as we suspect, indomethacin inhibits proteoglycan synthesis in disc tissue as it does in articular cartilage, then long-term administration of this agent may cause more harm than good.

' McKenzie LS, Horsburgh BA, Ghosh P, Taylor TKF. Osteoarthrosis: uncertain rationale for anti-inflammatory drug therapy. Lancet 1976; i:908-9.
${ }^{2}$ Roningen $\mathrm{H}$, Langeland $\mathrm{N}$. Indomethacin treatment in osteoarthritis of hip joint. Does the treatment interfere with the natural course of the disease? Acta Orthop Scand 1979;50:169.

${ }^{3}$ Milner JC. Osteoarthritis of the hip and indomethacin. $f$ Bone foint Surg 1972;54B :752.

${ }^{4}$ Solomon L. Drug-induced arthropathy and necrosis of the femoral head. $\mathcal{F}$ Bone foint Surg 1973;55B:242.

${ }^{5}$ Ro J, Sudmann E, Marton PF. Effect of indomethacin on fracture healing in rats. Acta Orthop Scand 1976;47:588.

(Accepted 6 fune 1981)

Raymond Purves Research Laboratories (University of Sydney), Royal North Shore Hospital of Sydney, St Leonards, New South Wales 2065, Australia

T K F TAYLOR, FRCS, FRACS, professor of orthopaedic and traumatic surgery

P GHOSH, PHD, FRACI, director of research

\section{Lyme arthritis appearing outside the United States: a case report from Switzerland}

Erythema chronicum migrans is an erythematous macule or papule that is thought to result from the bite of Ixodes ricinus, a tick very common in Europe. ${ }^{1}$ Erythema chronicum migrans has been reported in most European countries. ${ }^{2}$ It may be associated with a monoarticular or oligoarticular arthritis that occurs weeks to months after the skin lesions, and has been termed "Lyme arthritis." Since the first description of this new rheumatic disease, ${ }^{3}$ all the other observations have been made in the USA. We report a European case corresponding to the diagnostic criteria for Lyme arthritis. ${ }^{4}$ To our knowledge this is the first documented case recorded outside the USA.

\section{Case report}

A 68-year-old retired woman living in Payerne, a small town $45 \mathrm{~km}$ north of Lausanne, was bitten by an "insect" on the right thigh in August 1979. She developed a red papule, which in six weeks formed a large circle $24 \mathrm{~cm}$ in diameter. She had a dull pain at the area of the bite but no pruritus, fever, or headaches. Erythema chronicum migrans was diagnosed on 22 September 1979. The patient was given oral penicillin and the erythema faded quickly.

In mid-October 1979 she developed pain and stiffness in the right knee joint but was not seen by a rheumatologist until May 1980. Examination showed appreciable swelling of the right knee with local tenderness and a slight limitation of passive mobility, but no other abnormality. Erythrocyte sedimentation rate was $11 \mathrm{~mm}$ in first hour. Arthrocentesis yielded $15 \mathrm{ml}$ of straw-coloured synovial fluid with $3.5 \times 10^{9}$ leucocytes/1 (mainly polymorphonuclears); no crystals were seen on polarised light microscopy, and cultures were sterile. Ten days later there were $5 \mathrm{ml}$ of synovial fluid with $3 \cdot 2 \cdot 10^{9}$ leucocytes 1 . Agglutination titres against Coxiella burnetii were negative. Radiography of the knee was normal. Sulindac was given for three weeks and the swelling disappeared, but in the ensuing months mild pain persisted.

In March 1981 a follow-up showed no joint abnormality. Tests for rheumatoid factor and antinuclear antibodies were negative. The transient synovitis of the knee joint was diagnosed retrospectively as Lyme arthritis.

A questionnaire was sent to 14 patients in whom erythema chronicum migrans had been diagnosed between 1977 and 1980 in the dermatology clinic. Thirteen replied that they had had no joint pain after the skin eruption. One patient, a 45-year-old woman, said that nine months after an erythema chronicum migrans affecting the right leg she had suffered from pain in both knee joints, the left one having been swollen for several weeks. She had not consulted a physician, however, and the pain had subsided spontaneously after three months.

\section{Comment}

In our first patient there was no history of rheumatic complaints and no pertinent data to explain the origin of the arthritis; the temporal relation to erythema chronicum migrans and the subsequent disappearance of the symptoms made the diagnosis of Lyme arthritis very likely. It was based on clinical evidence as no specific tests are available. ${ }^{4}$ In the second case the diagnosis of Lyme arthritis can only be implied. 
Lyme arthritis has been reported so far only in the USA ${ }^{45}$; this study, however, suggests that it may also be found in Europe, and hence European doctors should be on the look out for new cases. It may frequently be missed since the onset of the arthritis may occur several months after the skin lesion has disappeared. ${ }^{4}$

${ }^{1}$ Aeschlimann A. Ixodes ricinus, Linné, 1758 (Ixodoidea; Ixodidae) Essai préliminaire de synthèse sur la biologie de cette espèce en Suisse. Acta Trop (Basel) 1972;29:321-40.

2 Golding D, Champion RH, Rook A, Roberts SOB. Erythema chronicum migrans in Britain. $\mathrm{Br}$ Med $\mathcal{F}$ 1978;ii:1087.

${ }^{3}$ Steere AC, Malawista SE, Snydan DR, Andiman WA. A cluster of arthritis in children and adults in Lyme Connecticut (abstract). Arthritis Rheum 1976;19:824.

4 Steere AC, Malawista SE, Hardin JA, Ruddy S, Askenase PW, Andiman WA. Erythema chronicum migrans and Lyme arthritis. The enlarging clinical spectrum. Ann Intern Med $1977 ; 86: 685-98$.

${ }^{5}$ Steere AC, Malawista SE. Cases of Lyme disease in the United States locations correlated with distribution of Ixodes dammini. Ann Intern Med $1979 ; 91: 730-3$.

(Accepted 19 fune 1981)

Rheumatology and Rehabilitation Centre, University Hospital, 1011 Lausanne, Switzerland

J C GERSTER, MD, consultant rheumatologist

SERGE GUGGI, MD, practitioner in internal medicine

Dermatology Clinic, University Hospital, 1011 Lausanne, Switzerland

HENRI PERROUD, MD, practitioner in dermatology

RENE BOVET, MD, senior registrar

\section{A case in favour of Poncet's disease}

Poncet $^{1}$ described a polyarthritis in the acute stage of extra-articular tuberculosis which eventually resolved without residual joint damage. This condition has been considered to be an allergic polyarthritis. ${ }^{2}$ Several case reports have been published, ${ }^{2-4}$ but there remains some controversy over whether the association is real or fortuitous. Summers and Jayson ${ }^{5}$ found no evidence of the condition in a detailed survey of 50 patients with active or treated tuberculosis, and they suggested that previous descriptions may have been due to chance.

I describe a patient in whom there was a strong temporal relation between episodes of polyarthritis and the presence of active tuberculosis.

\section{Case report}

A 34-year-old black Zambian man presented in February 1981 complaining of an unproductive cough, loss of appetite and wcight, and night sweats for about six weeks. He also complained of aching and stiffness of his wrists, elbows, ankles, and knees, and slight swelling of his knees for about eight weeks. The joint symptoms were present throughout the day but tended to be worse in the morning. Physical examination showed him to be reasonably well-nourished with a temperature of $38.1{ }^{\circ} \mathrm{C}$ and pulse of $94 / \mathrm{min}$. No rash was present. On auscultation of the chest coarse crepitations were heard over the right base posteriorly. There was a full range of movement of all the joints, though some pain was caused by full extension and flexion of the wrists, and slight periarticular swelling of the knees was found. The knees and wrists were warmer to touch than the surrounding skin; no joint effusions were present. A chest radiograph showed patchy shadowing at the right lower zone and right apex, fibrotic changes at the left apex, and specks of calcification in the left hilar lymph nodes. Sputum examination showed numerous acid-alcohol-fast bacilli, which on subsequent culture proved to be Mycobacterium tuberculosis. Haemoglobin concentration was $11.5 \mathrm{~g} / \mathrm{dl}$, erythrocyte sedimentation rate $96 \mathrm{~mm}$ in the first hour, and white cell count $8.2 \times 10^{9} / 1$. Radiographs of the wrists, elbows, knees and ankles showed no abnormality, and the result of a sheepcell agglutination test was negative. Pulmonary tuberculosis was diagnosed, and treatment was started with streptomycin $1 \mathrm{~g}$, thiacetazone $150 \mathrm{mg}$, and isoniazid $300 \mathrm{mg}$ daily. No specific treatment was given for the polyarthralgia, which was not severe. The patient's symptoms improved, and his sputum contained no $M$ tuberculosis after five weeks of treatment. The polyarthralgia and swelling of the knees improved progressively over about seven weeks, at which time his joints were normal on examination.

The joint symptoms had occurred on two previous occasions (1968 and
1974) when sputum-positive pulmonary tuberculosis had been diagnosed. The case notes confirmed that in 1968 he had complained of arthralgia of the wrists and knees, which preceded the diagnosis of tuberculosis by two months and which resolved within a month when antituberculous chemotherapy was given. In 1974 arthralgia and swelling of the wrists and knees began four months before tuberculosis was diagnosed, at which time a sterile clear effusion was present in the right knee joint. Radiographs of his wrists and knees had shown no abnormality, and the result of a sheep-cell agglutination test was negative. The joint symptoms and signs had resolved gradually over three months once antituberculous treatment was started.

$\mathrm{He}$ had not suffered polyarthralgia or joint swelling at any other time.

\section{Comment}

This patient suffered a low-grade polyarthritis each time he contracted pulmonary tuberculosis. Though the two conditions may have been associated by chance, this seemed unlikely in view of the recurrent association. The nature of the polyarthralgia and polyarthritis in this patient was similar to that described by Poncet. ${ }^{1}$ Symptoms of polyarthralgia and joint swelling preceded other symptoms of tuberculosis on all three occasions; it seems reasonable to suggest that tuberculosis should be included in the differential diagnosis of an unexplained polyarthralgia or polyarthritis.

${ }^{1}$ Poncet A. De la polyarthrite tuberculeuse déformante ou pseudorheumatisme chronique tuberculeux. Congrès Française de Chirurgie $1897 ; 1: 732-9$.

${ }^{2}$ Bloxham CA, Addy DP. Poncet's disease: parainfective tuberculous polyarthropathy. Br Med F 1978; : 1590-1.

${ }^{3}$ Isaacs AJ, Sturruck RD. Poncet's disease-fact or fiction? Tubercle $1974 ; 55: 135-42$

4 Greenwood BM. Polyarthritis in Western Nigeria. Ann Rheum Dis $1970 ; 29: 56-63$

5 Summers GD, Jayson MIV. Does Poncet's disease exist? Rheumatol Rehabil 1980;19:149-50.

(Accepted 2 fune 1981)

Department of Medicine, University Teaching Hospital, Lusaka, Zambia

S C ALLEN, BSC, MRCP, senior registrar

THE MEDLAR TREE grows near the bigness of the Quince Tree, spreading branches reasonably large, with longer and narrower leaves than either the apple or quince, and not dented about the edges. At the end of the sprigs stand the flowers, made of five white, great, broadpointed leaves, nicked in the middle with some white threads also; after which comes the fruit, of a brownish green colour, being ripe, bearing a crown as it were on the top, which were the five green leaves; and being rubbed off, or fallen away, the head of the fruit is seen to be somewhat hollow. The fruit is very harsh before it is mellowed, and has usually five kernels within it. There is another kind hereof nothing differing from the former, but that it hath some thorns on it in several places, which the other hath not; and usually the fruit is small, and not so pleasant. They grow in this land, and flower in May for the most part, and bear fruit in September and October.

The fruit is old Saturn's, and sure a better medicine he hardly hath to strengthen the retentive faculty; therefore it stays women's longings: The good old man cannot endure women's minds should run a gadding. Also a plaister made of the fruit dried before they are rotten, and other convenient things, and applied to the reins of the back, stops miscarriage in women with child. They are powerful to stay any fluxes of blood or humours in men or women; the leaves also have this quality. The decoction of them is good to gargle and wash the mouth, throat and teeth, when there is any defluxions of blood to stay it, or of humours, which causes the pains and swellings. It is a good bath for women, that have their courses flow too abundant: or for the piles when they bleed too much. If a poultice or plaister be made with dried medlars, beaten and mixed with the juice of red roses, whereunto a few cloves and nutmegs may be added, and a little red coral also, and applied to the stomach that is given to casting or loathing of meat, it effectually helps. The dried leaves in powder strewed on fresh bleeding wounds restrains the blood, and heals up the wound quickly. The medlar-stones made into powder, and drank in wine, wherein some Parsley-roots have lain infused all night, or a little boiled, do break the stone in the kidneys, helping to expel it. (Nicholas Culpeper (1616-54) The Complete Herbal, 1850.) 